\title{
Supporting the diagnosis of non-specific respiratory symptoms in primary care: the role of exhaled nitric oxide measurement and spirometry
}

\author{
${ }^{a}$ Research Fellow, Respiratory Research Department, Dunedin School of Medicine, Dunedin, New Zealand \\ ${ }^{b}$ Practice Nurse, M ornington Health Centre, Dunedin, New Zealand \\ c Principal General Practitioner, Mornington Health Centre, Dunedin \\ ${ }^{d}$ Research Technician, Respiratory Research Department, Dunedin School of Medicine \\ e Professor and Head of Department, Respiratory Research Department, Dunedin School of Medicine
}

Richard S Hew itt", Catherine M Modrich ${ }^{b}$, Timothy Medlicottc, Jan 0 Cowand, *D Robin Taylor

Received 29th August 2007; revised version received 31st January 2008; accepted 16th February 2008

\begin{abstract}
Aims: To assess whether exhaled nitric oxide $\left(\mathrm{FE}_{\mathrm{NO}}\right)$ measurements improve management and clinician confidence in patients presenting with non-specific respiratory symptoms.

Methods: This observational study was based in a large primary care practice (15,500 patients, 14 GPs). Patients had non-specific respiratory symptoms for at least six weeks. $\mathrm{FE}_{\mathrm{NO}}$ and spirometry measurements were performed at initial assessment. An algorithm was employed to assist interpretation of FENO and spirometry results. GPs evaluated the diagnostic contribution of FENO and spirometry at 3month follow-up.

Results: In $48 / 51(94 \%)$ of cases $\mathrm{FE}_{\mathrm{NO}}$ was considered significant in formulating a diagnosis. Spirometry was deemed helpful in $27 / 51$ $(54 \%)$.

Conclusion: $\mathrm{FE}_{\mathrm{NO}}$ measurements improved diagnostic confidence when assessing non-specific respiratory symptoms. This may be because, in contrast to spirometry, both low and high FENO values have clinical significance.

Trial registration: Australian Clinical Trials Registry ACTRN012605000354684

(c) 2008 General Practice Airways Group. All rights reserved.

RS Hewitt, et al. Prim Care Resp J 2008; 17(2): 97-103.

doi:10.3132/pcrj.2008.00025
\end{abstract}

Keyw ords diagnosis, asthma, exhaled nitric oxide, decision support, spirometry, respiratory symptoms

\section{Introduction}

Chronic cough, wheeze, and breathlessness are commonly encountered symptoms in primary care. Often they point to a diagnosis of asthma, ${ }^{1}$ but the symptoms are non-specific and there is an extensive differential diagnosis. Other conditions such as chronic obstructive pulmonary disease (COPD), gastro-oesophageal reflux disease (GORD), anxiety with hyperventilation, and mild bronchiectasis, may be wrongly identified as asthma and the patient managed inappropriately. In order to support a diagnosis, objective tests of airway physiology are often employed, such as spirometry, reversibility testing and peak expiratory flow (PEF) monitoring. However, obtaining serial PEFs is challenging and compliance is often poor. ${ }^{2}$ Their usefulness is also limited by poor sensitivity and specificity. ${ }^{3,4}$ Furthermore, they do not predict the likely response to inhaled corticosteroids (ICS) and such treatment is often initiated empirically. Prior prediction of steroid responsiveness would help to rationalise the management of chronic respiratory symptoms.

A common pathological feature of asthma is the presence of eosinophilic airway inflammation, although other histological subgroups are recognised. ${ }^{5}$ Importantly,

\footnotetext{
* Corresponding author: Professor D Robin Taylor, Respiratory Research Department, PO Box 913, Dunedin, New Zealand Tel: 006434740999 extension 8785 Fax: 006434776246 E-mail: robin.taylor@stonebow.otago.ac.nz
} 
eosinophilic airway inflammation is steroid responsive. ${ }^{6,7}$ Exhaled nitric oxide (FENO) correlates well with airway eosinophilia. ${ }^{8,9}$ The clinical significance of an elevated $\mathrm{FE}_{\mathrm{NO}}$ is not so much that it may help to distinguish asthma from nonasthma ${ }^{4,10}$ but, more importantly, it may be used as a predictor of steroid responsiveness. ${ }^{11,12}$ FENO measurements thus provide complementary information, not readily obtained from assessing symptoms and airway physiology.

The availability of diagnostic testing in primary care is limited. We undertook to make FENO measurements immediately available in a primary care setting. We hypothesised that, coupled with spirometry, this would improve diagnostic and therapeutic decision making as well as enhancing clinician confidence when assessing patients with non-specific respiratory symptoms.

\section{Methods}

\section{Subjects}

The study aims were explained to 14 general practitioners (GPs) in a large primary care practice $(15,500$ patients) in Dunedin, New Zealand at a practice management meeting. Thereafter, between July 2005 and June 2006, 55 patients, aged 12-80, with a history of cough, wheeze or shortness of breath for at least six weeks, were invited by their GP to participate. Patients were included if they had no previous respiratory diagnosis or if their previous diagnosis was uncertain, and were excluded if they had received oral or inhaled (including nasal) corticosteroids within the last six weeks. Smokers and recent ex-smokers (<6 months) were also excluded due to the confounding effect of smoking on

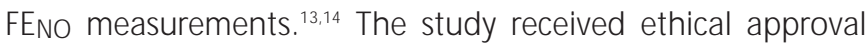
from the Lower South Regional Ethics Committee, and each participant gave written informed consent.

\section{Study design}

The study was observational. All patients were seen by their $\mathrm{GP}$ and then by the practice nurse. FENO measurement and spirometry were performed. Using these results, and with reference to an algorithm (Figure 1), the GP then made a provisional clinical diagnosis for each patient. The algorithm focused on whether or not the FENO result indicated a high, intermediate or low likelihood of eosinophilic airway inflammation and hence the potential for steroid responsiveness, rather than specific diagnostic labelling. The algorithm was based on published data defining the upper limit of normal for $\mathrm{FE}_{\mathrm{NO}} .{ }^{15,16}$ The GP then recorded a response to each of the following questions:

- Was there a prior diagnosis and if so, has it been confirmed or refuted?

- Was the availability of FENO significantly helpful in making the provisional diagnosis?

- Was the availability of spirometry significantly helpful in making the provisional diagnosis?

Management was then instituted based on clinical judgement and the results of the $\mathrm{FE}_{\mathrm{NO}}$ and spirometric tests as appropriate. Treatment decisions were not specifically prompted by the algorithm.

Figure 1. Algorithm given to GPs for interpretation of FENo and spirometry results at initial visit.

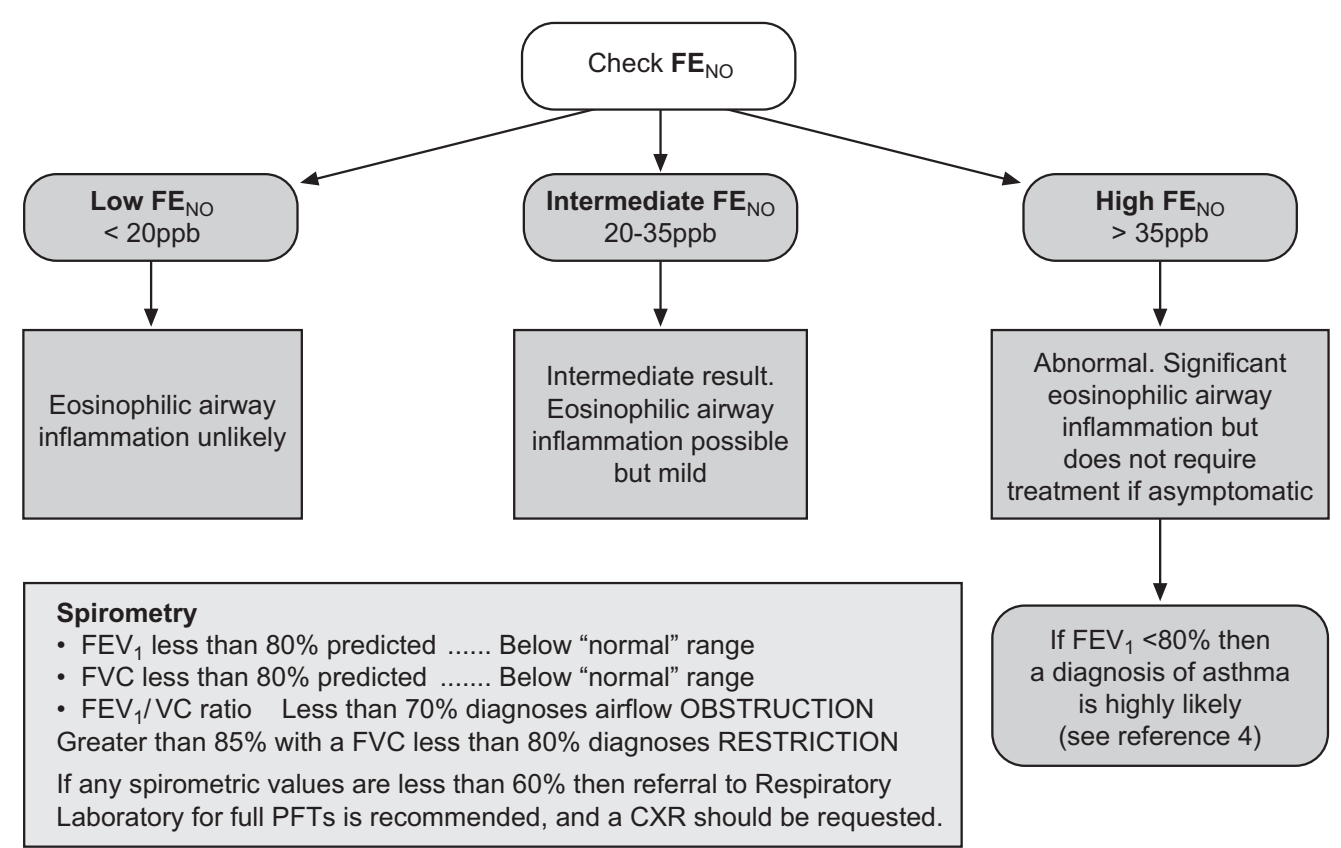


The final clinical diagnosis was made at 3 months in the light of the patient's clinical course, and was based on joint consultation between the GP and the research fellow (RSH), an advanced trainee in respiratory medicine. Further $\mathrm{FE}_{\mathrm{NO}}$ and/or spirometric measurements were available at that time at the discretion of the clinician.

For the purposes of this study, and given the study aims, a working diagnosis of atopic asthma was defined as variable respiratory symptoms with a $\mathrm{FE}_{\mathrm{NO}}$ level of $>35 \mathrm{ppb}$ and/or a positive response to a trial of corticosteroid, where such therapy had been administered.

\section{Study procedures}

FENO was measured according to current guidelines ${ }^{17}$ using a NIOX MINO electrochemical analyser ${ }^{18}$ or a NIOX chemiluminescence analyser (both Aerocrine, Solna, Sweden). The mean of two values was used. To validate FENo results, the sensors from the NIOX M INO device were tested at the end of the life time of each sensor against a calibrated standard, and where appropriate, a correction factor was applied to take account of signal drift. Where any later correction in the $\mathrm{FE}_{\mathrm{N} O}$ result affected the use of the diagnostic algorithm, that patient was excluded from analysis.

Spirometry was performed according to accepted standards ${ }^{19}$ using either a Spida 5 spirometer (M icro M edical, Rochester, Kent, UK) or a Vitalograph (Vitalograph Ltd, Buckingham, UK). The response to bronchodilator was not measured given that the presence or absence of response to bronchodilator is very poorly correlated with either the underlying pathological phenotype or potential improvements with inhaled corticosteroid therapy. ${ }^{20}$

\section{Results}

Of the 55 patients recruited, four were excluded because retrospective correction of $\mathrm{FE}_{\mathrm{NO}}$ results led to changes that affected the use of the diagnostic algorithm. Demographic details of the remaining 51 subjects are presented in Table 1. Detailed data for patients who were considered for inclusion but failed to satisfy inclusion criteria were not recorded.

\section{Initial diagnosis}

The diagnoses made at the first consultation were as follows: asthma ( $n=20,39.2 \%)$; non-specific cough ( $n=10,19.6 \%$ ); exercise-induced wheeze $(n=6,11.8 \%)$; extended post-viral respiratory syndrome $(n=5,9.8 \%)$; anxiety with hyperventilation $(n=4,7.8 \%)$; GORD $(n=3,5.9 \%)$; COPD $(n=$ $2,3.9 \%)$; and ACE inhibitor-induced cough ( $n=1,2.0 \%)$. Details regarding prior, initial and follow up diagnoses are given in Table 2. The diagnoses stratified by $\mathrm{FE}_{\mathrm{NO}}$ categories are shown in Table 3.

Thirty-four of the 51 patients had no previous diagnosis for their respiratory symptoms. Of the 17 patients who had a prior diagnosis, the diagnosis was changed at the initial study
Table 1. Demographic details of patients presenting with respiratory symptoms of $>6$ w eeks duration $(n=51)$.

\begin{tabular}{lcc} 
Age (years) & Mean 39.8 (range 12 - 76) \\
\hline Sex M / F & \multicolumn{2}{c}{18 / 33 } \\
\hline Smoking history (n) & $\begin{array}{c}\text { Ex-smoker } \\
19(37.3 \%)\end{array}$ & $\begin{array}{c}\text { Never smoked } \\
\text { (62.7\%) }\end{array}$ \\
\hline Prior history of ICS use & $>6$ weeks & Never \\
& previously & \\
& $14(27.5 \%)$ & $37(72.5 \%)$ \\
\hline $\begin{array}{l}\text { Duration of presenting } \\
\text { symptoms (weeks) }\end{array}$ & Median $16.0($ range $6-520)$ \\
\hline Symptoms (number of patients) & \\
$\quad$ Nocturnal wakening & $29(56.9 \%)$ \\
Cough & $44(86.3 \%)$ \\
Wheeze & $32(62.7 \%)$ \\
Shortness of breath & $44(86.3 \%)$
\end{tabular}

visit in five. Three of these five had low FE parts per billion (ppb)) and their diagnosis was changed from atopic asthma to either COPD ( $n=2$, FENO $8 p p b$ and $16.5 p p b)$ or non-atopic exercise-induced wheeze ( $n=1$, FENo $14.5 \mathrm{ppb})$. The two other patients, previously labelled as having COPD and angina, had high $\mathrm{FE}_{\mathrm{NO}}$ (50 and $106 \mathrm{ppb}$ respectively) and the diagnosis was changed to atopic asthma. In each case where the diagnosis was changed at the initial consultation, it was reconfirmed at 3-month follow-up. In the remaining 12 out of 17 patients, their prior diagnosis was confirmed as: atopic asthma $\left(n=6\right.$, geometric mean $\left.\mathrm{FE}_{\mathrm{NO}}=72.4 \mathrm{ppb}\right)$; GORD $\left(\mathrm{n}=3\right.$, geometric mean $\left.\mathrm{FE}_{\mathrm{NO}}=11.1 \mathrm{ppb}\right)$; non-specific cough $\left(n=2\right.$, geometric mean $\left.\mathrm{FE}_{\mathrm{NO}}=13.2 \mathrm{ppb}\right)$; and exercise-induced wheeze $\left(n=1, \mathrm{FE}_{\mathrm{NO}}=14.0 \mathrm{ppb}\right)$.

\section{Follow -up diagnosis}

The working diagnosis was changed at 3-month follow-up in 10 out of the 51 cases $(19.6 \%)$ - see Table 2 . Three patients initially diagnosed with atopic asthma received ICS treatment but their symptoms resolved and did not recur after the trial of steroid was concluded. They had high $\mathrm{FE}_{\mathrm{NO}}$ at their first visit but were subsequently shown to have low $\mathrm{FE}_{\mathrm{NO}}$ at least six weeks after discontinuing ICS treatment. The remaining patient with atopic asthma (FENO $20 \mathrm{ppb}$ ) was subsequently diagnosed as chronic cough of uncertain aetiology. Other changes in diagnosis included GORD to non-specific cough $\left(n=1, F_{N O} 8.1 p p b\right)$, post-viral respiratory syndrome to COPD $\left(n=1, F E_{N O} 18.5 p p b\right)$, and five patients in whom the diagnosis of chronic cough of uncertain aetiology was changed to either COPD ( $n=1, \mathrm{FE}_{\mathrm{NO}}$ 28.0ppb), post-viral respiratory syndrome $\left(n=2, F E_{N O} 13.0 p p b\right.$ and $\left.12.4 p p b\right), G O R D(n=1$, $\left.\mathrm{FE}_{\mathrm{NO}} 24.5 \mathrm{ppb}\right)$ or anxiety with hyperventilation $\left(\mathrm{n}=1, \mathrm{FE}_{\mathrm{NO}}\right.$ 14.0ppb). 
Table 2. Working diagnoses at presentation (initial diagnosis) and follow-up (3 months). The number of additions and subtractions is show $n$ to indicate $w$ here the working diagnosis $w$ as changed at each time point on the basis of FENo or spirometry results. See text for further details

\begin{tabular}{lccc} 
Diagnosis & Prior diagnosis & Initial diagnosis & Follow-up \\
$n$ & $n-3+14=20$ & $20-4=16$ & $10-5+2=7$ \\
\hline Atopic asthma & 9 & $2+8=10$ & 6 \\
\hline Non-specific cough & 2 & $1+5=6$ & $5+2=7$ \\
\hline Exercise induced wheeze (non-atopic) & 1 & 5 & $4+1=5$ \\
\hline Post-viral respiratory syndrome & - & 4 & $3-1+1=3$ \\
\hline Anxiety with hyperventilation & - & 3 & $2+1=3$ \\
\hline Gastro-oesophageal reflux disease & 3 & $1-1+2=2$ & 1 \\
\hline COPD & 1 & 1 & - \\
\hline ACE-inhibitor cough & 0 & $1-1=0$ & - \\
\hline Angina & 34 & - & 3
\end{tabular}

Table 3. Mean values (standard deviation) for FENo (geometric mean), FEV/ \% predicted and FEV $/ F V C$, stratified by FENo at initial diagnosis. ${ }^{1}$ Other low er respiratory tract pathology includes exercise-induced wheeze, chronic cough of unknown aetiology, extended post-viral respiratory syndrome and pneumonia. ${ }^{2}$ Non-respiratory pathology includes gastro-oesophageal reflux, anxiety with hyperventilation and ACE inhibitor-induced cough.

\begin{tabular}{|c|c|c|c|c|}
\hline FENO grouping & $\mathrm{N}$ & $\mathrm{FE}_{\mathrm{NO}}(\mathrm{ppb})$ & $\mathrm{FEV}_{1} \%$ predicted & $\mathrm{FEV}_{1} / \mathrm{FVC}$ ratio \\
\hline Asthma & 0 & - & - & - \\
\hline COPD & 2 & $11.2(1.7)$ & $37.4(21.9)$ & $50.4(14.8)$ \\
\hline Non-respiratory pathology 2 & 6 & $10.9(1.4)$ & $105.9(15.2)$ & $81.8(4.5)$ \\
\hline Intermediate $\mathrm{FE}_{\mathrm{NO}}(20-35 \mathrm{ppb})$ & 12 & $23.9(1.1)$ & $95.6(10.3)$ & $81.6(5.6)$ \\
\hline Asthma & 3 & $24.7(1.3)$ & $84.7(12.9)$ & $75.9(3.6)$ \\
\hline High $\mathrm{FE}_{\mathrm{NO}}(>35 \mathrm{ppb})$ & 17 & $73.2(1.7)$ & $85.0(27.5)$ & $73.6(12.1)$ \\
\hline Asthma & 17 & $73.2(1.7)$ & $85.0(27.5)$ & $73.6(12.1)$ \\
\hline COPD & 0 & & - & - \\
\hline Other LRT pathology & 0 & & - & - \\
\hline Non-respiratory pathology & 0 & & - & - \\
\hline
\end{tabular}




\section{Response to treatment in relation to $\mathrm{FE}_{\mathrm{NO}}$}

Of the 22 patients with low $\mathrm{FE}_{\mathrm{NO}}$, the algorithm was overruled in three, and they were given ICS treatment. How ever, none of these three were deemed to have obtained a beneficial clinical response. Similarly three out of 12 patients with intermediate $\mathrm{FE}_{\mathrm{NO}}$ (in the range $20-35 \mathrm{ppb}$ ) were given ICS, two-thirds of whom were adjudged to have benefited. All of the 17 patients who had high $\mathrm{FE}_{\mathrm{NO}}(>35 \mathrm{ppb})$ readings were subsequently treated with ICS. Fourteen out of the 17 showed a satisfactory clinical response as judged by their GP at follow up. Three subjects who did not show any improvement with ICS had that treatment withdrawn; their symptoms subsequently resolved and they all had low FENO at follow-up.

\section{Clinician appraisal of diagnostic tests}

GPs adjudged that arriving at a working diagnosis was significantly helped by access to $\mathrm{FE}_{\mathrm{NO}}$ in 48 out of 51 (94\%) cases, and by spirometry in 27 out of $51(53 \%)$ cases. In the three cases where $\mathrm{FE}_{\mathrm{N} O}$ was not considered to be helpful, FENO was either low (14.0ppb) or intermediate (20.0 and $23.0 \mathrm{ppb})$. These three patients had normal spirometry and were diagnosed as having non-atopic exercise-induced wheeze based on their history. For spirometry, in all 24 cases where it was deemed not to have been helpful, the results were normal. In the 27 cases where spirometry was considered helpful it was abnormal in only six cases, all of whom had an obstructive defect (FEV $/ / F V C$ ratio $<0.7)$. Four of these six were diagnosed with atopic asthma (geometric mean FENO 130.3ppb (SD 34.0)) and the remaining two as COPD (geometric mean FE $\mathrm{NO}_{\mathrm{NO}} 11.5 \mathrm{ppb}$ (SD 6.0)).

\section{Discussion}

The results of the present study confirm that FENO $_{\text {NO }}$ measurements obtained in a primary care setting offer helpful diagnostic information. Our aim was to demonstrate that immediate availability of $\mathrm{FE}_{\mathrm{NO}}$, coupled with spirometry, would improve diagnostic confidence and therapeutic decision making in managing patients with non-specific respiratory symptoms. In $94 \%$ of cases, the clinicians deemed this to be the case.

Initially, an empirical approach is often adopted in the management of airways-related symptoms. Later, objective tests may be sought to clarify or support the diagnosis, particularly if symptoms are persistent or troublesome. The latter are important given the non-specific nature of cough, wheeze and dyspnoea. Distinguishing asthma (or perhaps more appropriately "steroid-responsive airways disease") from other conditions such as post-viral bronchial hyperresponsiveness, COPD, GORD and anxiety-hyperventilation is important, given that both the anticipated natural history and therapeutic decisions in favour of using inhaled anti- inflammatory treatment will be influenced by such distinctions.

Unfortunately, conventional lung function tests provide only indirect evidence regarding either the aetiology of respiratory symptoms i.e. airflow obstruction, or the likelihood of steroid-responsiveness. ${ }^{20}$ Although undoubtedly important, notably for identifying patients with COPD, ${ }^{21}$ spirometry is not widely available. Quality assurance is also a major issue, ${ }^{22}$ as is the case for serial PEF recordings. ${ }^{2}$ Even when performed adequately, spirometry is poorly sensitive in diagnosing asthma, or in identifying the cause of non-specific cough. ${ }^{23}$ Thus, in a study from the United States, although $66 \%$ of surveyed primary care practices owned a spirometer, only $50 \%$ of patients with suspected asthma had spirometry performed. The most commonly cited reason for not doing so was a perceived lack of impact that the results would have on clinical decision-making. ${ }^{24}$ Overall, our results are consistent with that perception: spirometry was normal in the majority of patients $(45 / 51,88 \%)$, and was only considered helpful in aiding a diagnosis in $53 \%$ of cases.

In contrast, the perceived relevance and yield from FENO measurements in our study was much greater at $94 \%$. There are several reasons for this. Firstly, FENO measurements are a surrogate marker for eosinophilic airway inflammation, ${ }^{8,9,25}$ which in turn indicates the likelihood of steroid responsiveness. ${ }^{6.7}$ Hence in patients with non-specific respiratory symptoms and high $\mathrm{FE}_{\mathrm{NO}}$ levels, a positive response to ICS may be anticipated. ${ }^{14} \mathrm{FE}_{\mathrm{NO}}$ results not only provide insight regarding the underlying airway pathology (the presence or absence of eosinophilic airway inflammation), but also guidance regarding specific treatment. This is not the case for spirometry. Whether or not to prescribe a trial of ICS is often decided empirically, and this aspect of management was simplified in our study using

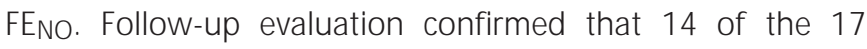
patients with a high FENO $_{\text {NO }}$ had a satisfactory clinical response when treated with ICS.

Secondly, both low and high $\mathrm{FE}_{\mathrm{NO}}$ levels are meaningful in the interpretation of respiratory symptoms. ${ }^{26}$ This is not the case for changes in lung function, where only low values are clinically instructive.

Despite the fact that access to $\mathrm{FE}_{\mathrm{NO}}$ improved diagnostic confidence, the follow-up diagnosis at 3-month review was different in 10 out of 51 cases $(20 \%)$. FENO was either intermediate $(n=2)$ or low $(n=5)$ and the diagnoses given at initial presentation and follow-up included GORD, nonspecific cough, post-viral respiratory syndrome and anxiety hyperventilation. Neither FENO $_{\mathrm{NO}}$ measurements nor spirometry categorically distinguish between these various conditions and so it is perhaps not surprising that after observing the natural history of the patients' symptoms for three months, 
the initial diagnoses were altered. This does not negate the usefulness of FENO in these cases. Low values may identify the absence of potentially steroid responsive airway pathology. ${ }^{14}$ It is also important to note that in three out of 10 patients, elevated $\mathrm{FE}_{\mathrm{NO}}$ levels occurred only transiently, and their initial diagnosis of eosinophilic asthma was changed. This highlights a significant interpretive issue with regard to $\mathrm{FE}_{\mathrm{NO}}$. Transiently elevated levels may occur with limited exposure to allergen, ${ }^{27}$ or with viral infection. ${ }^{28}$ Although we sought to avoid this by enrolling patients whose symptoms were present for six weeks or longer, it remained an issue. It is also possible that such patients might have had symptomatically intermittent atopic asthma characterised by improved symptoms and normalised $\mathrm{FE}_{\mathrm{NO}}$ levels, which might later recur. Our followup interval was not sufficiently long to confirm or deny this possibility. Alternatively these elevated FENO results may have been false positives. Discordance between high $\mathrm{FE}_{\mathrm{NO}}$ levels and corresponding induced sputum eosinophil counts has been reported. ${ }^{8}$

Our study was not designed to repeat earlier more robust studies to investigate the utility of FENO measurements, , $^{4,10,14}$ but to assess their usefulness in a busy general practice. Perhaps the study would have been strengthened if repeated measurements, application of the algorithm, and applying a priori treatment options had all been obligatory rather than optional. But this was not a controlled trial: it was set up to be a "real world" evaluation. Furthermore, smokers and recent ex-smokers were excluded from participation. Arguably, diagnostic testing is even just as important in this group. However, given that $\mathrm{FE}_{\mathrm{NO}}$ measurements are significantly lower in smokers, and the interpretation of results is problematic, we opted not to include current or exsmokers. ${ }^{11,12}$

Obtaining reliable $\mathrm{FE}_{\mathrm{NO}}$ measurements is an easily learned skill for both patient and practitioner. The test is reproducible, acceptable and achievable in the vast majority of patients from the age of 6 upwards. The results are available almost immediately and therefore clinical decisions can be made promptly. The development of less expensive portable devices ${ }^{18}$ is set to make $\mathrm{FE}_{\mathrm{NO}}$ analysis much more accessible, including in primary care. We deliberately chose to trial the use of a portable device in a large primary care health centre, and we demonstrated that it is a feasible option in the context of running a busy practice. Although we did not undertake a cost-benefit analysis, economies of scale are likely to operate in this setting, given the very frequent need to diagnose and treat non-specific respiratory complaints. Potentially one of the other major economic benefits would be a reduction in the costs of unnecessary inhaled corticosteroid prescribing.

In conclusion, there is a need for diagnostic support in primary care regarding the likely cause of chronic respiratory symptoms. When provided, such support has the potential to improve not only the standards of patient care but also clinician satisfaction. ${ }^{29}$ Conventional tests such as spirometry are limited in the information they can provide. $\mathrm{FE}_{\mathrm{NO}}$ measurements are reliable and easily performed, and provide complementary data which inform the assessment and management of patients with an exceedingly common clinical presentation.

\section{Acknow ledgements}

The authors wish to thank the general practitioners, nursing staff and patients of the M ornington Health Centre for their help with this study. The study was supported by the Strategic Research Initiative 2005, awarded by the Dean of the Dunedin School of Medicine of the University of Otago. Dr Hewitt was in receipt of an unrestricted educational grant from Aerocrine $A B$, Solna, Sweden, in order to conduct this study. Dr Hewitt also received the Tony Hocken Research Scholarship for 12 months - from the Department of M edicine, Dunedin School of M edicine - during the course of this study.

The nitric oxide analysers used in this study were donated to the Mornington Health Centre by Aerocrine, Solna, Sweden.

\section{Conflict of interest declaration}

Professor D Robin Taylor has received lecture fees from Aerocrine (Solna, Sweden). There are no competing interests for any other author.

\section{References}

1. GINA, Global strategy for asthma management and prevention: NHLBI/WHO Workshop Report. NHLBI Publication, 2007: p. Update 2006.

2. Moscato G, Godnic-Cvar J, Maestrelli P, Malo JL, Burge PS, Coifman R. Statement on self-monitoring of peak expiratory flows in the investigation of occupational asthma. Subcommittee on Occupational Allergy of the European Academy of Allergology and Clinical Immunology. American Academy of Allergy and Clinical Immunology. European Respiratory Society. American College of Allergy, Asthma and Immunology. Eur Respir J 1995;8(9):1605-10.

3. Hunter CJ, Brightling CE, Woltmann G, Wardlaw AJ, Pavord ID. A comparison of the validity of different diagnostic tests in adults with asthma. Chest 2002;121(4):1051-7

4. Smith AD, Cowan JO, Filsell S et al. Diagnosing asthma: comparisons between exhaled nitric oxide measurements and conventional tests. Am J Respir Crit Care M ed 2004; 169(4):473-8. Epub 2003 Nov 25.

5. Simpson JL, Scott R, Boyle MJ, Gibson PG. Inflammatory subtypes in asthma: assessment and identification using induced sputum. Respirology 2006;11(1):54-61.

6. Pizzichini M M. Is sputum eosinophilia a good or poor predictor of benefit from inhaled corticosteroid therapy in asthma? Eur Respir J 2002;20(6):1359-61.

7. Brightling $C E, M$ onteiro $W$, Ward $R$, et al. Sputum eosinophilia and short-term response to prednisolone in chronic obstructive pulmonary disease: a randomised controlled trial. Lancet 2000;356(9240):1480-5.

8. Berry MA, Shaw, DE, Green RH, Brightling CE, Wardlaw AJ, Pavord ID. The use of exhaled nitric oxide concentration to identify eosinophilic airway inflammation: an observational study in adults with asthma. Clin Exp Allergy 2005;35(9):1175-9.

9. Warke TJ, Fitch PS, Brown V, et al. Exhaled nitric oxide correlates with airway eosinophils in childhood asthma. Thorax 2002;57(5):383-7.

10. Dupont LJ, Demedts MG, Verleden GM. Prospective evaluation of the validity of exhaled nitric oxide for the diagnosis of asthma. Chest 2003;123(3): 751-6.

11. Kharitonov SA, Robbins RA, Yates D, Keatings V, Barnes PJ. Acute and chronic 
effects of cigarette smoking on exhaled nitric oxide. Am J Respir Crit Care Med 1995;152(2):609-12.

12. MCSharry CP, MCKay IC, Chaudhuri R, Livingston E, Fraser I, Thomson NC. Short and long-term effects of cigarette smoking independently influence exhaled nitric oxide concentration in asthma. J Allergy Clin Immunol 2005; 116(1):88-93.

13. Little SA, Chalmers GW, MacLeod KJ, M CSharry C, Thomson NC. Non-invasive markers of airway inflammation as predictors of oral steroid responsiveness in asthma. Thorax 2000;55(3):232-4.

14. Smith AD, Cowan JO, Brassett KP, et al. Exhaled Nitric Oxide: A Predictor of Steroid Response. Am J Respir Crit Care Med 2005;18:18.

15. Jones SL, Kittelson J, Cowan JO, et al. The predictive value of exhaled nitric oxide measurements in assessing changes in asthma control. Am J Respir Crit Care Med 2001; 164(5):738-43.

16. Kharitonov SA, Gonio F, Kelly C, M eah S, Barnes PJ. Reproducibility of exhaled nitric oxide measurements in healthy and asthmatic adults and children. Eur Respir J 2003;21(3):433-8.

17. ATS/ERS Recommendations for Standardized Procedures for the Online and Offline M easurement of Exhaled Lower Respiratory Nitric Oxide and Nasal Nitric Oxide, 2005. Am J Respir Crit Care Med 2005;171(8):912-30.

18. Alving $K$, Janson C, Nordvall L. Performance of a new hand-held device for exhaled nitric oxide measurement in adults and children. Respir Res 2006; 7:67.

19. Miller MR, Hankinson J, Brusasco V, et al. Standardisation of spirometry. Eur Respir J 2005;26(2):319-38.

20. Kerstjens HA, Brand PL, Quanjer PH, van der Bruggen-Bogaarts BA, Koeter GH, Postma DS. Variability of bronchodilator response and effects of inhaled corticosteroid treatment in obstructive airways disease. Dutch CNSLD Study Group. Thorax 1993;48(7):722-9.

21. Petty TL. Benefits of and barriers to the widespread use of spirometry. Curr
Opin Pulm Med 2005;11(2):115-20.

22. Eaton T, Withy S, Garrett JE, Mercer J, Whitlock RM, Rea HH. Spirometry in primary care practice: the importance of quality assurance and the impact of spirometry workshops. Chest 1999;116(2):416-23.

23. Thiadens HA, De Bock GH, Van Houwelingen JC, et al. Can peak expiratory flow measurements reliably identify the presence of airway obstruction and bronchodilator response as assessed by $\mathrm{FEV}(1)$ in primary care patients presenting with a persistent cough? Thorax 1999;54(12):1055-60.

24. Kaminsky DA, Marcy TW, Bachand M, Irvin CG. Knowledge and use of office spirometry for the detection of chronic obstructive pulmonary disease by primary care physicians. Respir Care 2005;50(12):1639-48.

25. Jatakanon A, Lim S, Kharitonov SA, Chung KF, Barnes PJ. Correlation between exhaled nitric oxide, sputum eosinophils, and methacholine responsiveness in patients with mild asthma. Thorax 1998;53(2):91-5.

26. Taylor DR, Pijnenburg MW, Smith AD, De Jongste JC. Exhaled nitric oxide measurements: clinical application and interpretation. Thorax 2006;61(9):81727.

27. Kharitonov SA, O'Connor BJ, Evans DJ, Barnes PJ. Allergen-induced late asthmatic reactions are associated with elevation of exhaled nitric oxide. Am J Respir Crit Care Med 1995; 151(6):1894-9.

28. Sanders SP, Siekierski ES, Richards SM, Porter JD, Imani F, Proud D. Rhinovirus infection induces expression of type 2 nitric oxide synthase in human respiratory epithelial cells in vitro and in vivo. J Allergy Clin Immunol 2001;107(2):235-43.

29. Hassett $R, M$ eade $K$, Partridge MR. Enhancing the accuracy of respiratory diagnoses in primary care: a report on the establishment of a Community Respiratory Assessment Unit. Prim Care Resp J 2006;15(6):354-61. doi:10.1016/j.pcrj.2006.10.003

\section{Available online at http://www thepcrj.org}

